Pacific Journal of Mathematics

SUMMABILITY OF FOURIER SERIES BY TRIANGULAR 


\title{
SUMMABILITY OF FOURIER SERIES BY TRIANGULAR MATRIX TRANSFORMATIONS
}

\author{
H. P. Dikshit
}

Hille and Tamarkin have proved a result for the Nörlund summability of the Fourier series of $f(t)$ at $t=x$, under the hypothesis (i) $\varphi(t)=\{f(x+t)+f(x-t)-2 f(x)\} / 2=o(1), t \rightarrow 0$, which includes as a special case the corresponding result for the Cesàro summability. However, under the lighter condition (ii) $\int_{0}^{t} \varphi(u) d u=o(t), t \rightarrow 0$, Astrachan has proved a theorem for the Nörlund summability which does not cover the corresponding Cesàro case. The object of the present paper is to prove theorems for the Nörlund summability and another triangular matrix method of summability which are subtler than Astrachan's theorem in the sense that they include as a special case the corresponding result for the Cesàro summability.

1. Definitions and notations. Let $\sum_{n=0}^{\infty} v_{n}$ be a given infinite series with the sequence of partial sums $\left\{s_{n}\right\}$. We shall consider sequence-to-sequence transformation of the type

$$
u_{n}=\sum_{k=0}^{\infty} d_{n k} s_{k}
$$

in which the elements of the matrix $D=\left(\left(d_{n k}\right)\right)$ are real or complex constants and $d_{n k}=0$ for $k>n$. The sequence $\left\{u_{n}\right\}$ is said to be the sequence of $D$-means of $\left\{s_{n}\right\}$. If $\lim _{n \rightarrow \infty} u_{n}$ exists and is equal to $u$ then we say that the series $\sum_{n=0}^{\infty} v_{n}$ or the sequence $\left\{s_{n}\right\}$ is summable $D$ to the sum $u$.

Let $\left\{p_{n}\right\}$ be a sequence of constants, real or complex and let us write $P_{n}=p_{0}+p_{1}+\cdots+p_{n} \neq 0, P_{-1}=p_{-1}=0$. Then the matrix $D$ defines a Nörlund matrix $\left(N, p_{n}\right)[7]$, if

$$
d_{n k}=p_{n-k} / P_{n}, \quad(n \geqq k \geqq 0) .
$$

The conditions for the regularity of the $\left(N, p_{n}\right)$ mean are

$$
\lim _{n \rightarrow \infty} p_{n} / P_{n}=0 \text { and } \sum_{k=0}^{n}\left|p_{k}\right|=O\left(\left|P_{n}\right|\right), \quad n \rightarrow \infty .
$$

In the special case in which

$$
p_{n}=\left(\begin{array}{c}
n+\alpha-1 \\
\alpha-1
\end{array}\right)=\frac{\Gamma(n+\alpha)}{\Gamma(n+1) \Gamma(\alpha)} \quad(\alpha>-1)
$$

the $\left(N, p_{n}\right)$ mean reduces to the familiar $(C, \alpha)$ mean.

The product of the matrix $(C, 1)$ with the matrix $\left(N, p_{n}\right)$ defines 
the matrix $(C, 1) \cdot\left(N, p_{n}\right)$. Thus $D$ defines the matrix $(C, 1) \cdot\left(N, p_{n}\right)$ if

$$
d_{n k}=\frac{1}{n+1} \sum_{\nu=k}^{n} p_{\nu-k} / P_{\nu}, \quad(0 \leqq k \leqq n) .
$$

Similarly, one defines the $\left(N, p_{n}\right) \cdot(C, 1)$ matrix as a product of the $\left(N, p_{n}\right)$ matrix with the $(C, 1)$ matrix. In Astrachan's notations [1] the $\left(N, p_{n}\right) \cdot(C, 1)$ summability is denoted by $\left(N, p_{n}\right) \cdot C_{1}$.

Let $f(t)$ be a periodic function, with period $2 \pi$ and integrable in the sense of Lebesgue over $(-\pi, \pi)$. We assume without any loss of generality that the constant term in the Fourier series of $f(t)$ is zero, so that $\int_{-\pi}^{\pi} f(t) d t=0$ and

$$
f(t) \sim \sum_{n=1}^{\infty}\left(a_{n} \cos n t+b_{n} \sin n t\right) .
$$

We write throughout:

$$
\begin{aligned}
\varphi(t) & =\frac{1}{2}\{f(x+t)+f(x-t)-2 f(x)\} ; \\
\Phi_{\alpha}(t) & =\frac{1}{\Gamma(\alpha)} \int_{0}^{t}(t-u)^{\alpha-1} \varphi(u) d u, \alpha>0 ; \Phi_{0}(t)=\varphi(t) ; \\
\varphi_{\alpha}(t) & =\Gamma(\alpha+1) \Phi_{\alpha}(t) / t^{\alpha} ; \alpha \geqq 0 ; \\
R_{n} & =n p_{n} / P_{n} ; S_{n}=\sum_{\nu=0}^{n} P_{\nu}(\nu+1)^{-1} / P_{n} ; \\
\Delta \mu_{n} & , \text { or more precisely } \Delta_{n} \mu_{n}=\mu_{n}-\mu_{n+1} ; \\
\tau & =[1 / t] ; P_{[\lambda]}=P(\lambda) ; p_{[\lambda]}=p(\lambda) ;
\end{aligned}
$$

where $[\lambda]$ denotes the greatest integer not greater than $\lambda$.

$K$, denotes a positive constant not necessarily the same at each occurrence.

2. Introduction. Concerning the Cesàro summability of Fourier series Bosanquet [2] has proved the following.

TheoRem A. If $\varphi_{\alpha}(t)=o(1)$ as $t \rightarrow 0$, then the Fourier series of $f(t)$, at $t=x$, is summable $(C, \alpha+\delta)$ for every $\delta>0$ and $\alpha \geqq 0$.

Theorem A is known to be the best possible in the sense that it breaks down if $\delta=0$.

For the Nörlund summability of Fourier series we have the following result due to Hille and Tamarkin [5].

THEOREM B. A regular $\left(N, p_{n}\right)$ method is Fourier effective, if the sequence $\left\{p_{n}\right\}$ satisfies tho hypotheses: 


$$
\begin{aligned}
R_{n} & =O(1), \\
\sum_{k=1}^{n} k\left|\Delta p_{k-1}\right| & =O\left(\left|P_{n}\right|\right), \\
\sum_{k=1}^{n}\left|P_{k}\right| / k & =O\left(\left|P_{n}\right|\right),
\end{aligned}
$$

as $n \rightarrow \infty$.

Theorem B implies inter alia that if $\varphi(t)=o(1)$ as $t \rightarrow 0$, and $\left\{p_{n}\right\}$ satisfies the hypotheses (2.1)-(2.3), then the Fourier series of $f(t)$ is summable by a regular $\left(N, p_{n}\right)$ method.

Replacing the hypothesis: $\varphi(t)=o(1)$ as $t \rightarrow 0$ of Theorem B by the lighter hypothesis: $\varphi_{1}(t)=o(1)$ as $t \rightarrow 0$, Astrachan [1] proved the following.

Theorem C. A regular $\left(N, p_{n}\right)$ method is $K_{\alpha}$ effective $(0<\alpha \leqq 1)$, if the sequence $\left\{p_{n}\right\}$ satisfies the hypotheses (2.1), (2.2) and

$$
\begin{aligned}
\sum_{k=1}^{n} k(n-k)\left|\Delta^{2} p_{k-2}\right| & =O\left(\left|P_{n}\right|\right), \\
\sum_{k=1}^{n}\left|P_{k}\right| / k^{2} & =O\left(\left|P_{n}\right| / n\right),
\end{aligned}
$$

as $n \rightarrow \infty$.

Hille and Tamarkin have also pointed out in [5] that the sequence $\left\{p_{n}\right\}$ defined by (1.4) satisfies the hypotheses of Theorem B for $1>\alpha>0$ and therefore, $(C, \alpha)$ summability for such a $\alpha$ is Fourier effective. Thus Bosanquet's Theorem A when $\alpha=0$ is an immediate consequence of Theorem B. It is therefore natural to expect that the hypothesis: $\varphi_{1}(t)=o(1)$ as $t \rightarrow 0$, may lead to $\left(N, p_{n}\right)$ summability of the Fourier series of $f(t)$ and that such a result may include Theorem A when $\alpha=1$, as a special case. However, Astrachan's Theorem $\mathrm{C}$ in this direction only implies the summability $(C, \delta)$ for $\delta \geqq 2$, whereas one needs the summability $(C, \delta), \delta>1$, in order to cover Bosanquet's Theorem A when $\alpha=1$. Thus there is a gap of approximately 1 between the orders of $(C)$ summability implied by Theorem $\mathrm{C}$ and the corresponding case of Theorem A. This emerges from the following reasoning.

The result of Lemma 8.1 in Astrachan [1], which is required for the proof of his Theorem $\mathrm{C}$ states that

$$
\sum_{k=0}^{n}(n-k)\left|\Delta^{2} p_{k-2}\right|=O\left(\left|P_{n}\right| / n\right),
$$

as $n \rightarrow \infty$. Since the left hand side of (2.6) is greater than $K n$ we 
observe that $K n^{2} \leqq\left|P_{n}\right|$. It may be pointed out that for Astrachan's proof of Lemma 8.1 one has to assume $p_{0}=0$.

The object of our Theorem 1 is to show that it is indeed, possible to obtain a result for the $\left(N, p_{n}\right)$ summability of Fourier series which has also the scope of covering Bosanquet's Theorem A for $\alpha=1$.

Astrachan [1, Th. II] has also obtained the following result for the $\left(N, p_{n}\right) \cdot(C, 1)$ summability of the Fourier series.

Theorem D. The $\left(N, p_{n}\right) \cdot(C, 1)$ method is $K_{\alpha}$ effective $(0<\alpha \leqq 1)$ provided the sequence $\left\{p_{n}\right\}$ satisfies the hypotheses (2.1)-(2.3) and the regularity condition (1.3).

Due to possible oversight, Astrachan has not shown that the regularity conditions follow from his statement of Theorem D. Further, his proof of Theorem D contains a deficiency, which has been pointed out and supplied by the present author in [4].

Silverman has shown in [8, Th. 1] that a necessary and sufficient condition for a $\left(N, p_{n}\right)$ matrix to be permutable with the $(C, 1)$ matrix is that it be a Cesàro matrix. This implies that

$$
(C, 1) \cdot\left(N, p_{n}\right) \neq\left(N, p_{n}\right) \cdot(C, 1)
$$

except when $\left\{p_{n}\right\}$ is defined by (1.4). In view of this Astrachan's technique of obtaining his Theorem $D$ from Theorem $B$ fails in the case of the $(C, 1) \cdot\left(N, p_{n}\right)$ summability and one has to give a direct proof to conclude the $(C, 1) \cdot\left(N, p_{n}\right)$ summability of Fourier series of $f(t)$ under the hypothesis: $\varphi_{1}(t)=o(1)$ as $t \rightarrow 0$. More precisely, we observe that since the $(C, 1)$ mean is a very special case of the $\left(N, p_{n}\right)$ mean viz. the case in which $p_{n}=1$, the convenience of expressing the $(C, 1)$ mean of the Fourier series of $f(t)$, essentially as a difference of the Fejér's and Dirichlet's kernels of $\varphi_{1}(t)[1$, p. 546], disappears totally in the case of the $\left(N, p_{n}\right)$ mean.

Thus for the $(C, 1) \cdot\left(N, p_{n}\right)$ summability of Fourier series, we obtain Theorem 2 which also covers Theorem A when $\alpha=1$.

3. We prove the following results.

THEOREM 1. If $\varphi_{1}(t)=o(1)$ as $t \rightarrow 0$ and $\left\{p_{n}\right\}$ is nonnegative, monotonic nondecreasing sequence such that $p_{n} \rightarrow \infty$ as $n \rightarrow \infty,\left\{p_{n+1}-p_{n}\right\}$ is nonincreasing, $R_{n}=O(1)$ and (2.5) holds, then the Fourier series of $f(t)$, at $t=x$, is summable $\left(N, p_{n}\right)$.

THEOREM 2. If $\varphi_{1}(t)=o(1)$ as $t \rightarrow 0$ and $\left\{p_{n}\right\}$ is a nonnegative, monotonic nonincreasing sequence such that $S_{n}=O(1)$, then the Fourier series of $f(t)$, at $t=x$, is summable $(C, 1) \cdot\left(N, p_{n}\right)$. 
REMARKs. It is easy to see that if $\left\{p_{n}\right\}$ is nonnegative and nondecreasing then $(n+1) p_{n} \geqq P_{n}$ and therefore $S_{n}=O(1)$. Further, in this case

$$
\sum_{k=1}^{n} k\left|\Delta p_{k-1}\right|=-\sum_{k=1}^{n-1} \sum_{\mu=1}^{k}\left(p_{\mu}-p_{\mu-1}\right)+n \sum_{\mu=1}^{n}\left(p_{\mu}-p_{\mu-1}\right)=O\left(P_{n}\right),
$$

if $R_{n}=O(1)$. Thus the sequence $\left\{p_{n}\right\}$ used in Theorem 1 also satisfies the hypotheses of Theorem $B$.

As demonstrated by the present author in [3] if $\left\{p_{n}\right\}$ is a nonnegative sequence then the hypotheses: $R_{n}=O(1)$ and $S_{n}=O(1)$ imply that

$$
P_{k} \sum_{n=k+1}^{\infty} \frac{1}{(n+1) P_{n-1}}=O(1), \quad(k=1,2,3, \cdots),
$$

from which it is immediate that $P_{n} \rightarrow \infty$ as $n \rightarrow \infty$. It may be observed that with a slight modification in author's analysis in [3] it is possible to even drop the condition $R_{n}=O(1)$ to get the same conclusion.

4. We require the following lemmas for the proof of our results.

LEMMA 1. If $\left\{q_{n}\right\}$ is nonnegative and nonincreasing, then for $0 \leqq a \leqq b \leqq \infty$ and $0 \leqq t \leqq \pi$,

$$
\left|\sum_{k=a}^{b} q_{k} \exp i k t\right| \leqq K Q_{\tau},
$$

where $\tau=[1 / t]$ and $Q_{m}=q_{0}+q_{1}+\cdots+q_{m}$.

This lemma may be proved by following the technique of proof of Lemma 5.11 in McFadden [6].

Lemma 2. If $\left\{p_{n}\right\}$ is a nonnegative and monotonic nondecreasing sequence such that $\left\{p_{n+1}-p_{n}\right\}$ is nonincreasing and $R_{n}=O(1)$, then as $n \rightarrow \infty$

$$
\sum_{k=0}^{n} p_{k}(n-k) \exp (i k t)=O\left(n P_{\tau}\right)+O\left(t^{-2} p_{n}\right)
$$

uniformly in $0<t \leqq \pi$.

Proof. We write by Abel's transformation

$$
\begin{aligned}
\sum_{k=0}^{n} & p_{k}(n-k) \exp (i k t) \\
& =\sum_{k=0}^{n-1} \Delta_{k}\left\{p_{k}(n-k)\right\} \sum_{\nu=0}^{k} \exp (i \nu t) \\
& =(1-\exp i t)^{-1}\left[\sum_{k=0}^{n-1} \Delta_{k}\left\{p_{k}(n-k)\right\}-\sum_{k=0}^{n-1} \Delta_{k}\left\{p_{k}(n-k)\right\} \exp i(k+1) t\right]
\end{aligned}
$$




$$
\begin{aligned}
& =(1-\exp i t)^{-1}\left[n p_{0}-\sum_{k=0}^{n-1}(n-k) \Delta p_{k} \exp i(k+1)-\sum_{k=0}^{n-1} p_{k+1} \exp i(k+1) t\right] \\
& =(1-\exp i t)^{-1}\left[n p_{0}-\sum_{k=0}^{n-1} \sum_{\nu=0}^{k} \Delta p_{\nu} \exp i(\nu+1) t-\sum_{k=0}^{n-1} p_{k+1} \exp i(k+1) t\right] .
\end{aligned}
$$

Thus

$$
\begin{aligned}
& \left|\sum_{k=0}^{n} p_{k}(n-k) \exp i k t\right| \\
& \quad \leqq|1-\exp i t|^{-1}\left[n p_{0}+\sum_{k=0}^{n-1}\left|\sum_{\nu=0}^{k} \Delta p_{\nu} \exp i(\nu+1) t\right|+\left|\sum_{k=0}^{n-1} p_{k+1} \exp i(k+1) t\right|\right] \\
& \quad \leqq K t^{-1}\left[n p_{0}+K \sum_{k=0}^{n-1} \sum_{\nu=0}^{\tau}\left(p_{\nu+1}-p_{\nu}\right)+p_{n} \max _{1 \leqq \nu \leqq n}\left|\sum_{k=1}^{\nu} \exp i k t\right|\right]
\end{aligned}
$$

(by Lemma 1 and Abel's Lemma, since $\left\{p_{\nu+1}-p_{\nu}\right\}$ is nonnegative, nonincreasing and $\left\{p_{n}\right\}$ is nondecreasing)

$\leqq K t^{-1}\left[n p_{0}+K n p_{\tau+1}+K p_{n} t^{-1}\right]$

$\leqq K n t^{-1} p_{\tau+1}+K t^{-2} p_{n}$

$\leqq K n P_{\tau}+K t^{-2} p_{n}$,

since $\left\{p_{n}\right\}$ is nondecreasing and $R_{n}=O(1)$ which also implies $P_{n+1} / P_{n}=O(1)$. This completes the proof of Lemma 2.

LEMMA 3. If $\left\{p_{n}\right\}$ is nonnegative and nonincreasing, then as $n \rightarrow \infty$

$$
\sum_{\nu=0}^{n} \frac{1}{P_{\nu}} \sum_{k=0}^{\nu}(\nu-k) p_{k} \exp i(\nu-k) t=O\left(t^{-2}\right)+O\left(t^{-1} P_{t} \sum_{\nu=\tau}^{n} \frac{1}{P_{\nu}}\right)+O\left(\frac{n t^{-1} P_{\tau}}{P_{n+1}}\right),
$$

uniformly in $0<t \leqq \pi$.

Proof. Applying Abel's transformation we get

$$
\begin{aligned}
\sum_{\nu=k}^{n} \frac{\nu-k}{P_{\nu}} \exp i(\nu-k) t \\
=\sum_{\nu=k}^{n} \Delta_{\nu}\left(\frac{\nu-k}{P_{\nu}}\right) \sum_{\mu=k}^{\nu} \exp i(\mu-k) t+\frac{n-k+1}{P_{n+1}} \sum_{\mu=k}^{n} \exp i(\mu-k) t \\
=(1-\exp i t)^{-1}\left[\sum_{\nu=k}^{n} \Delta_{\nu}\left(\frac{\nu-k}{P_{\nu}}\right)\{1-\exp i(\nu-k+1) t\}\right. \\
\left.\quad \quad+\frac{n-k+1}{P_{n+1}}\{1-\exp i(n-k+1) t\}\right] \\
\quad(1-\exp i t)^{-1}\left[-\sum_{\nu=k}^{n} \frac{p_{\nu+1}}{P_{\nu} P_{\nu+1}}(\nu-k) \exp i(\nu-k+1) t\right. \\
\left.\quad+\sum_{\nu=k}^{n} \frac{1}{P_{\nu+1}} \exp i(\nu-k+1) t-\frac{n-k+1}{P_{n+1}} \exp i(n-k+1) t\right] .
\end{aligned}
$$

Changing the order of summation of the inner sums, thus we have 


$$
\begin{aligned}
\sum \equiv & \left|\sum_{\nu=0}^{n} \frac{1}{P_{\nu}} \sum_{k=0}^{\nu}(\nu-k) p_{k} \exp i(\nu-k) t\right| \\
= & \left|\sum_{k=0}^{n} p_{k} \sum_{\nu=k}^{n} \frac{\nu-k}{P_{\nu}} \exp i(\nu-k) t\right| \\
\leqq & K t^{-1}\left[\left|\sum_{k=0}^{n} p_{k} \sum_{\nu=k}^{n} \frac{p_{\nu+1}}{P_{\nu} P_{\nu+1}}(\nu-k) \exp i(\nu-k+1) t\right|\right. \\
& +\left|\sum_{k=0}^{n} p_{k} \sum_{\nu=k}^{n} \frac{1}{P_{\nu+1}} \exp i(\nu-k+1) t\right| \\
& \left.+\frac{1}{P_{n+1}}\left|\sum_{k=0}^{n} p_{k}(n-k+1) \exp i(n-k+1) t\right|\right] \\
= & \sum_{1}+\sum_{2}+\sum_{3},
\end{aligned}
$$

say.

Again by a change of order of summation we have

$$
\begin{aligned}
\sum_{1} & \leqq K t^{-1} \sum_{\nu=0}^{n} \frac{p_{\nu+1}}{P_{\nu} P_{\nu+1}}\left|\sum_{k=0}^{\nu} p_{k}(\nu-k) \exp i(\nu-k+1) t\right| \\
& \leqq K t^{-1} \sum_{\nu=0}^{\tau-1} \frac{R_{\nu+1}}{P_{\nu}} \sum_{k=0}^{\nu} p_{k}+K t^{-1} \sum_{\nu=\tau}^{n} \frac{R_{\nu+1}}{P_{\nu}} \max _{0 \leqq \rho \leqq}\left|\sum_{k=0}^{\rho} p_{k} \exp i(\nu-k+1) t\right|
\end{aligned}
$$

(by Abel's Lemma. If $\tau=0$ the first part is taken as 0 .)

$$
\leqq K t^{-2}+K t^{-1} P_{\tau} \sum_{\nu=\tau}^{n} \frac{1}{P_{\nu}}
$$

by virtue of Lemma 1 and the fact that $(n+1) p_{n} \leqq P_{n}$.

Similarly,

$$
\begin{aligned}
\sum_{2} & \leqq K t^{-1} \sum_{\nu=0}^{n} \frac{1}{P_{\nu+1}}\left|\sum_{k=0}^{\nu} p_{k} \exp i(\nu-k+1) t\right| \\
& \leqq K t^{-1} \sum_{\nu=0}^{\tau-1} \frac{1}{P_{\nu+1}} \sum_{k=0}^{\nu} p_{k}+K t^{-1} \sum_{\nu=\tau}^{n} \frac{1}{P_{\nu+1}} P_{\tau} \\
& \leqq K t^{-1}+K t^{-1} P_{\tau} \sum_{\nu=\tau}^{n} \frac{1}{P_{\nu}}
\end{aligned}
$$

by Lemma 1.

Finally, by Lemma 1 and Abel's Lemma we have

$$
\sum_{3} \leqq K t^{-1} \frac{n}{P_{n+1}} P_{\tau}
$$

This completes the proof of Lemma 3 .

5. Proof of Theorem 1. For the Fourier series of $f(t)$, at $t=x$ we have 


$$
s_{k}(x)-f(x)=\frac{1}{\pi} \int_{0}^{\pi} \varphi(t) \frac{\sin (k+1 / 2) t}{\sin (t / 2)} d t .
$$

Therefore, if $t_{n}$ denotes the $\left(N, p_{n}\right)$ mean of $\left\{s_{k}(x)\right\}$ then

$$
t_{n}-f(x)=\frac{1}{\pi P_{n}} \int_{0}^{\pi} \varphi(t)\left\{\sum_{k=0}^{n} p_{n-k} \frac{\sin (k+1 / 2) t}{\sin (t / 2)}\right\} d t .
$$

Integrating by parts, we get

$$
\begin{aligned}
t_{n}-f(x)= & \frac{\Phi_{1}(\pi)}{\pi P_{n}} \sum_{k=0}^{n} p_{n-k}(-1)^{k} \\
& -\frac{1}{\pi P_{n}} \int_{0}^{\pi} \frac{\Phi_{1}(t)}{\sin (t / 2)}\left\{\sum_{k=0}^{n} p_{n-k} k \cos \left(k+\frac{1}{2}\right) t\right\} d t \\
& -\frac{1}{2 \pi P_{n}} \int_{0}^{\pi} \frac{\Phi_{1}(t)}{\sin (t / 2)}\left\{\sum_{k=0}^{n} p_{n-k} \cos \left(k+\frac{1}{2}\right) t\right\} d t \\
& +\frac{1}{2 \pi P_{n}} \int_{0}^{\pi} \frac{\Phi_{1}(t)}{\tan (t / 2)}\left\{\sum_{k=0}^{n} p_{n-k} \frac{\sin (k+1 / 2) t}{\sin (t / 2)}\right\} d t \\
= & L_{1}+L_{2}+L_{3}+L_{\triangleleft},
\end{aligned}
$$

say.

Thus, in order to prove the theorem it is sufficient to show that as $n \rightarrow \infty$,

$$
L_{j}=o(1) ; \quad(j=1,2,3 \text { and } 4) .
$$

Since $\Phi_{1}(t) \cot t / 2=o(1)$ as $t \rightarrow 0$, it follows from Theorem B that $L_{4}=o(1)$ as $n \rightarrow \infty$, when one appeals to the remarks contained in $\S 3$ of the present paper.

We write

$$
\frac{1}{P_{n}}\left|\sum_{k=0}^{n} p_{n-k}(-1)^{k}\right| \leqq K \frac{p_{n}}{P_{n}}=o(1),
$$

as $n \rightarrow \infty$, since $\left\{p_{n}\right\}$ is nonnegative and nondecreasing and $R_{n}=O(1)$. Thus, we have $L_{1}=o(1)$ as $n \rightarrow \infty$.

Also, $L_{3}=o(1)$ as $n \rightarrow \infty$, by virtue of Riemann-Lebesgue Theorem and the regularity of the $\left(N, p_{n}\right)$ mean which is implied by the hypotheses: $\left\{p_{n}\right\}$ is nonnegative and $R_{n}=O(1)$.

Finally, to show that $L_{2}=o(1)$ as $n \rightarrow \infty$, we observe that

$$
\frac{\Phi_{1}(t)}{\sin t / 2}=o(1)
$$

as $t \rightarrow 0$ and that the kernel occuring in $L_{2}$ is the real part of the complex valued function

$$
\frac{1}{\pi P_{n}}\left\{\exp -i\left(n+\frac{1}{2}\right) t\right\} \sum_{k=0}^{n} p_{k}(n-k) \exp i k t=M_{n}(t),
$$

say. 
Therefore, in order to prove that $L_{2}=o(1)$ as $n \rightarrow \infty$, it is enough to show that as $n \rightarrow \infty$

$$
I \equiv \int_{0}^{\pi} g(t) M_{n}(t) d t=o(1),
$$

where $g(t)=o(1)$ as $t \rightarrow 0$.

We write, for a fixed $\delta$ such that $0<\delta \leqq \pi$,

$$
I=\left(\int_{0}^{n^{-1}}+\int_{n^{-1}}^{\delta}+\int_{\delta}^{\pi}\right) g(t) M_{n}(t) d t=I_{1}+I_{2}+I_{3},
$$

say.

Since

$$
M_{n}(t)=O\left(\frac{1}{P_{n}} \sum_{k=0}^{n} p_{k}(n-k)\right)=O(n),
$$

we have, as $n \rightarrow \infty$

$$
I_{1}=O\left(n \int_{0}^{n^{-1}}|g(t)| d t\right)=o(1) .
$$

For the interval $o<\delta \leqq t \leqq \pi$, we have from Lemma 2

$$
M_{n}(t)=O\left(\frac{n}{P_{n}}\right)+O\left(\frac{p_{n}}{P_{n}}\right)=O\left(\frac{1}{p_{n}}\right)+o(1)=o(1),
$$

as $n \rightarrow \infty$, by the hypotheses: $R_{n}=O(1)$ and that $p_{n} \rightarrow \infty$ as $n \rightarrow \infty$. Therefore, as $n \rightarrow \infty$,

$$
I_{3}=o(1) .
$$

Since $g(t)=o(1)$ as $t \rightarrow 0$, to demonstrate the truth of $I_{2}=o(1)$ as $n \rightarrow \infty$ we prove that

$$
I_{2}^{*} \equiv \int_{n^{-1}}^{\delta}\left|M_{n}(t)\right| d t \leqq K .
$$

By Lemma 2, we have

$$
\begin{aligned}
I_{2}^{*} & \leqq K \frac{n}{P_{n}} \int_{n^{-1}}^{\delta} P(1 / t) d t+K \frac{p_{n}}{P_{n}} \int_{n^{-1}}^{\delta} t^{-2} d t \\
& =K \frac{n}{P_{n}} \int_{\delta}^{n-1} \frac{P(s)}{s^{2}} d s+K R_{n}, \\
& \leqq K,
\end{aligned}
$$

by virtue of the hypotheses: $R_{n}=O(1)$ and (2.5). Thus, as $n \rightarrow \infty$.

$$
I_{2}=o(1) \text {. }
$$


Combining (5.3)-(5.6), we get (5.2) and therefore $L_{2}=o(1)$ as $n \rightarrow \infty$. This completes the proof of Theorem 1 .

6. Proof of Theorem 2. If $t_{n}^{1}$ denotes the $(C, 1) \cdot\left(N, p_{n}\right)$ mean of the sequence $\left\{s_{k}(x)\right\}$ then

$$
\begin{aligned}
t_{n}^{1}-f(x) & =\frac{1}{n+1} \sum_{k=0}^{n} \sum_{\nu=k}^{n} \frac{p_{\nu-k}}{P_{\nu}} s_{k}(x)-f(x) \\
& =\frac{1}{n+1} \sum_{\nu=0}^{n} \frac{1}{P_{\nu}} \sum_{k=0}^{\nu} p_{\nu-k} s_{k}(x)-f(x) \\
& =\frac{1}{(n+1) \pi} \int_{0}^{\pi} \varphi(t)\left\{\sum_{\nu=0}^{n} \frac{1}{P_{\nu}} \sum_{k=0}^{\nu} p_{\nu-k} \frac{\sin (k+1 / 2) t}{\sin (t / 2)}\right\} d t .
\end{aligned}
$$

Integrating by parts, we get

$$
\begin{aligned}
t_{n}^{1}-f(x)= & \frac{\Phi_{1}(\pi)}{\pi(n+1)} \sum_{\nu=0}^{n} \frac{1}{P_{\nu}} \sum_{k=0}^{\nu} p_{\nu-k}(-1)^{k} \\
& -\frac{1}{\pi(n+1)} \int_{0}^{\pi} \frac{\Phi_{1}(t)}{\sin (t / 2)}\left\{\sum_{\nu=0}^{n} \frac{1}{P_{\nu}} \sum_{k=0}^{\nu} p_{\nu-k} k \cos \left(k+\frac{1}{2}\right) t\right\} d t \\
& -\frac{1}{2 \pi(n+1)} \int_{0}^{\pi} \frac{\Phi_{1}(t)}{\sin (t / 2)}\left\{\sum_{\nu=0}^{n} \frac{1}{P_{\nu}} \sum_{k=0}^{\nu} p_{\nu-k} \cos \left(k+\frac{1}{2}\right) t\right\} d t \\
& +\frac{1}{2 \pi(n+1)} \int_{0}^{\pi} \frac{\Phi_{1}(t)}{\tan (t / 2)}\left\{\sum_{\nu=0}^{n} \frac{1}{P_{\nu}} \sum_{k=0}^{\nu} p_{\nu-k} \frac{\sin [k+(1 / 2)] t}{\sin (t / 2)}\right\} d t \\
= & C_{1}+C_{2}+C_{3}+C_{4},
\end{aligned}
$$

say.

Thus, in order to prove the theorem it is sufficient to show that as $n \rightarrow \infty$

$$
C_{j}=o(1) ; \quad(j=1,2,3 \text { and } 4) .
$$

Since $\left\{p_{n}\right\}$ is nonnegative and nonincreasing, we have by Abel's Lemma

$$
\frac{1}{P_{\nu}}\left|\sum_{k=0}^{\nu} p_{\nu-k}(-1)^{k}\right| \leqq K \frac{p_{0}}{P_{\nu}}=o(1) ，
$$

as $\nu \rightarrow \infty$, by virtue of the fact that $P_{n} \rightarrow \infty$ as $n \rightarrow \infty$. By virtue of the regularity of the $(C, 1)$ mean we now get $C_{1}=o(1)$ as $n \rightarrow \infty$.

Further, since $\left[\Phi_{1}(t) / \sin (t / 2)\right] \cos t / 2=o(1)$ as $t \rightarrow 0$ and the $(C, 1)$ mean is regular, Theorem $\mathrm{B}$ implies that $C_{4}=o(1)$ as $n \rightarrow \infty$, when one observes that the sequence $\left\{p_{n}\right\}$ used in our Theorem 2 satisfies all the hypotheses of Theorem $B$.

That $C_{3}=o(1)$ as $n \rightarrow \infty$, follows from the Riemann-Lebesgue Theorem and the fact that the $(C, 1)$ and the $\left(N, p_{n}\right)$ mean are both regular. 
Finally, we observe that $\left[\Phi_{1}(t) / \sin (t / 2)\right]=o(1)$ as $t \rightarrow 0$ and therefore, in order to prove that $C_{2}=o(1)$ as $n \rightarrow \infty$, it is sufficient to show that as $n \rightarrow \infty$

$$
E \equiv \int_{0}^{\pi} g(t) J_{n}(t) d t=o(1),
$$

where $g(t)=o(1)$ as $t \rightarrow 0$ and

$$
J_{n}(t)=\frac{\exp (i t / 2)}{\pi(n+1)} \sum_{\nu=0}^{n} \frac{1}{P_{\nu}} \sum_{k=0}^{\nu}(\nu-k) p_{k} \exp i(\nu-k) t .
$$

Let us write for a fixed $\delta$ such that $0<\delta \leqq \pi$,

$$
E=\left(\int_{0}^{n^{-1}}+\int_{n^{-1}}^{\delta}+\int_{\delta}^{\pi}\right) g(t) J_{n}(t) d t=E_{1}+E_{2}+E_{3},
$$

say. Since

$$
\left|J_{n}(t)\right|<\frac{1}{n+1} \sum_{\nu=0}^{n} \frac{1}{P_{\nu}} \sum_{k=0}^{\nu}(\nu-k) p_{k} \leqq K n,
$$

we have as $n \rightarrow \infty$

$$
E_{1}=O\left(n \int_{0}^{n^{-1}}(g(t)) d t\right)=o(1) .
$$

For the interval $0<\delta \leqq t \leqq \pi$, we have by Lemma 3

$$
J_{n}(t)=o(1)+O\left(\frac{1}{n+1} \sum_{\nu=0}^{n} \frac{1}{P_{\nu}}\right)+O\left(\frac{1}{P_{n+1}}\right)=o(1)
$$

as $n \rightarrow \infty$, since $P_{n} \rightarrow \infty$ as $n \rightarrow \infty$ and $(C, 1)$ mean is regular. Thus, as $n \rightarrow \infty$,

$$
E_{3}=o(1) \text {. }
$$

Since $g(t)=o(1)$ as $t \rightarrow 0$, to prove that $E_{2}=o(1)$ as $n \rightarrow \infty$, it is enough to demonstrate that

$$
E_{2}^{*}=\int_{n-1}^{\delta}\left|J_{n}(t)\right| d t \leqq K .
$$

By Lemma 3 we get

$$
\begin{aligned}
E_{2}^{*} \leqq & \frac{K}{n+1} \int_{n^{-1}}^{\delta} \frac{d t}{t^{2}}+\frac{K}{n+1} \int_{n^{-1}}^{\delta} \frac{P(1 / t)}{t}\left\{\sum_{\nu=[1 / t]}^{n} \frac{1}{P_{\nu}}\right\} d t \\
& +\frac{K}{P_{n}} \int_{n^{-1}}^{\delta} \frac{P(1 / t)}{t} d t \\
\leqq & K+\frac{K}{n+1} \int_{\delta}^{n} \frac{P(s)}{s}\left\{\sum_{\nu=[s]}^{n} \frac{1}{P_{\nu}}\right\} d s+K \frac{1}{P_{n}} \int_{\delta^{-1}}^{n} \frac{P(s)}{s} d s \\
\leqq & K+\frac{K}{n+1} \int_{\delta}^{n} \frac{P(s)}{s}\left\{\sum_{\nu=[s]}^{n} \frac{1}{P_{\nu}}\right\} d s,
\end{aligned}
$$


since $S_{n}=O(1)$. That $E_{2}^{*} \leqq K$, now follows from the fact that

$$
\begin{aligned}
\frac{1}{n+1} \sum_{k=1}^{n} \frac{P_{k}}{k} \sum_{\nu=k}^{n} \frac{1}{P_{\nu}} & =\frac{1}{n+1} \sum_{\nu=1}^{n} \frac{1}{P_{\nu}} \sum_{k=1}^{\nu} \frac{P_{k}}{k} \\
& =\frac{1}{n+1} \sum_{\nu=1}^{n} S_{\nu} \leqq K,
\end{aligned}
$$

since $S_{n}=O(1)$. Therefore, as $n \rightarrow \infty$

$$
E_{2}=o(1) \text {. }
$$

Combining (6.3)-(6.6), we get (6.2) and therefore, $C_{2}=o(1)$ as $n \rightarrow \infty$.

This completes the proof of Theorem 2 .

\section{REFERENCES}

1. Max Astrachan, Studies in the summability of Fourier series by Nörlund means, Duke Math. J. 2 (1936), 543-568.

2. L. S. Bosanquet, On the summability of Fourier series, Proc. London Math. Soc. 31 (1930), 144-164.

3. H. P. Dikshit, Absolute summability of Fourier series by Nörlund means, Math. Zeit. 102 (1967), 166-170.

4. - A note on a theorem of Astrachan on the $\left(N, p_{n}\right) \cdot(C, 1)$ summability of Fourier series, Math. Student 33 (1964), 77-79.

5. E. Hille and J. D. Tamarkin, On the summability of Fourier series I, Trans. Amer. Math. Soc. 34 (1932), 757-783.

6. L. McFadden, Absolute Nörlund summability, Duke Math. J. 9 (1942), 168-207.

7. N. E. Nörlund, Sur une application des fonctions permutables, Lunds Universitets Årsskrift (2) 16 (1919).

8. S. L. Silverman, Products of Nörlund transformation, Bull. Amer. Math. Soc. 43 (1937), 95-101.

Received May 3, 1968.

UNIVERSITY OF Allahabad

Allahabad, India 


\title{
PACIFIC JOURNAL OF MATHEMATICS
}

\author{
EDITORS
}

H. ROYDEN

Stanford University

Stanford, California

R. R. PhelPS

University of Washington

Seattle, Washington 98105
J. DUGUNDJI

Department of Mathematics

University of Southern California

Los Angeles, California 90007

RICHARD ARENS

University of California

Los Angeles, California 90024

\section{ASSOCIATE EDITORS}
E. F. BECKENBACH
B. H. NeumanN
F. WOLF
K. YoSHIDA

\section{SUPPORTING INSTITUTIONS}

\author{
UNIVERSITY OF BRITISH COLUMBIA \\ CALIFORNIA INSTITUTE OF TECHNOLOGY \\ UNIVERSITY OF CALIFORNIA \\ MONTANA STATE UNIVERSITY \\ UNIVERSITY OF NEVADA \\ NEW MEXICO STATE UNIVERSITY \\ OREGON STATE UNIVERSITY \\ UNIVERSITY OF OREGON \\ OSAKA UNIVERSITY \\ UNIVERSITY OF SOUTHERN CALIFORNIA
}

\author{
STANFORD UNIVERSITY \\ UNIVERSITY OF TOKYO \\ UNIVERSITY OF UTAH \\ WASHINGTON STATE UNIVERSITY \\ UNIVERSITY OF WASHINGTON \\ $\stackrel{*}{*} \stackrel{*}{*}{ }^{*}{ }^{*}$ \\ CHEVRON RESEARCH CORPORATION \\ TRW SYSTEMS \\ NAVAL WEAPONS CENTER
}

The Supporting Institutions listed above contribute to the cost of publication of this Journal, but they are not owners or publishers and have no responsibility for its content or policies.

Mathematical papers intended for publication in the Pacific Journal of Mathematics should be in typed form or offset-reproduced, double spaced with large margins. Underline Greek letters in red, German in green, and script in blue. The first paragraph or two must be capable of being used separately as a synopsis of the entire paper. It should not contain references to the bibliography. Manuscripts, in duplicate if possible, may be sent to any one of the four editors. Please classify according to the scheme of Math. Rev. 36, 1539-1546. All other communications to the editors should be addressed to the managing editor, Richard Arens, University of California, Los Angeles, California, 90024.

50 reprints are provided free for each article; additional copies may be obtained at cost in multiples of 50 .

The Pacific Journal of Mathematics is published monthly. Effective with Volume 16 the price per volume (3 numbers) is $\$ 8.00$; single issues, $\$ 3.00$. Special price for current issues to individual faculty members of supporting institutions and to individual members of the American Mathematical Society: $\$ 4.00$ per volume; single issues $\$ 1.50$. Back numbers are available.

Subscriptions, orders for back numbers, and changes of address should be sent to Pacific Journal of Mathematics, 103 Highland Boulevard, Berkeley, California, 94708.

PUBLISHED BY PACIFIC JOURNAL OF MATHEMATICS, A NON-PROFIT CORPORATION

Printed at Kokusai Bunken Insatsusha (International Academic Printing Co., Ltd.), 7-17, Fujimi 2-chome, Chiyoda-ku, Tokyo, Japan. 


\section{Pacific Journal of Mathematics \\ Vol. 30, No. $2 \quad$ October, 1969}

Gregory Frank Bachelis, Homomorphisms of annihilator Banach algebras.

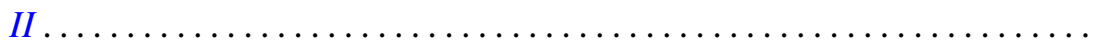

Leon Bernstein and Helmut Hasse, An explicit formula for the units of an algebraic number field of degree $n \geq 2 \ldots \ldots \ldots \ldots \ldots \ldots \ldots . \ldots 29$

David W. Boyd, Best constants in a class of integral inequalities ........ 367

Paul F. Conrad and John Dauns, An embedding theorem for lattice-ordered

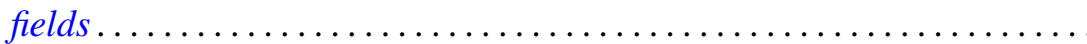

H. P. Dikshit, Summability of Fourier series by triangular matrix

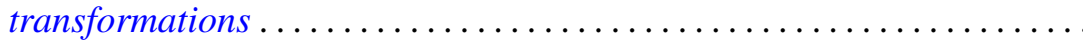

Dragomir Z. Djokovic, Linear transformations of tensor products preserving a fixed rank............................. 411

John J. F. Fournier, Extensions of a Fourier multiplier theorem of Paley . . . 415 Robert Paul Kopp, A subcollection of algebras in a collection of Banach

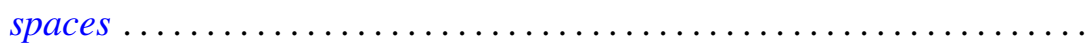

Lawrence Louis Larmore, Twisted cohomology and enumeration of vector bundles ...................................... 437

William Grenfell Leavitt and Yu-Lee Lee, A radical coinciding with the lower radical in associative and alternative rings .................

Samuel Merrill and Nand Lal, Characterization of certain invariant subspaces of $H^{p}$ and $L^{p}$ spaces derived from logmodular

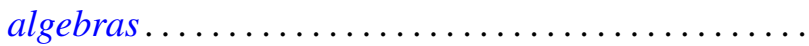

Sam Bernard Nadler, Jr., Multi-valued contraction mappings ....

T. V. Panchapagesan, Semi-groups of scalar type operators in Banach spaces ....................................

J. W. Spellmann, Concerning the infinite differentiability of semigroup motions

H. M. (Hari Mohan) Srivastava, A note on certain dual series equations involving Laguerre polynomials.

Ernest Lester Stitzinger, A nonimbedding theorem of associative algebras................................

J. Jerry Uhl, Jr., Martingales of vector valued set functions ...

John Mays Worrell Jr., On continuous mappings of metacompact $\check{C} e c h$

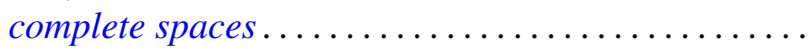

